ISBN 978-93-84422-76-9

6th International Conference on Developments in Engineering and Technology

(ICDET-2017)

Bangkok (Thailand) Feb.6-7, 2017

\title{
Two types of Twin Roll Casters for Aluminium Alloy Clad Strip
}

\author{
Toshio Haga \\ Department of Mechanical Engineering, Osaka Institute of Technology, Japan
}

\begin{abstract}
It became clear that the clad ratio of a three-layer clad strip cast by a vertical type tandem twin roll caster (VTTRC) can be controlled by the solidification length. The clad ratio of about 1:8:1 was attained in a three-layer clad strip of 3003 aluminium alloy as the base strip and 4045 aluminium alloy as the overlay strips. The clad ratio was not changed by cold rolling. Bonding was not influenced by the clad ratio. However, porosities or gaps (no bonding area) appeared at the interfaces of the clad strip consisting of Al-Mg alloy and other aluminium alloys due primarily to melting, oxidation and insufficient temperature-rise of the strip. A vertical type twin roll caster equipped with a scraper (VTRCS) was then developed. The VTRCS could cast sound clad strips, including the Al-Mg alloy strips. By using the scraper, which prevented melting, oxidation and insufficient temperature-rise, the clad strips consisting of the Al-Mg alloy strips could be cast without the defects at the interface.
\end{abstract}

Keywords: clad strip, twin roll caster, Al-Mg alloy, scraper

\section{Introduction}

In the conventional process for fabricating clad strips of aluminium alloys, many processes and a great deal of energy are used. For example, D.C. casting, scalping, hot rolling and cold rolling are used to make single strips. Moreover, cleaning the strip, edge welding and hot rolling are used to bond single strips into the clad strip. Therefore, processing and energy savings in the fabrication of clad strips have been demanded. To achieve these savings, a vertical type tandem twin roll caster (VTTRC) was proposed [1]. This twin roll caster can cast threelayer clad strips directly from molten metal. Copper rolls are used to increase the casting speed, and the roll speed is as high as $30 \mathrm{~m} / \mathrm{min}$. For example, sound clad strips of Al-Mn and Al-Si can be cast. The molten metals do not mix and the interface between the strips is clear. In addition, the element of one strip does not diffuse into the other strips, and the strips are strongly bonded at the interface. These results show that the VTTRC satisfies some of the problems for saving processing and energy in the fabrication of clad strips. However, other properties of the VTTRC must be investigated. For example, these properties include control of the clad ratio and casting of a clad strip consisting of $\mathrm{Al}-\mathrm{Mg}$ alloy and other aluminium alloys. In the fabrication of the clad strip, the control of the clad ratio is important. Casting conditions to control the clad ratio in the casting of the clad strip by the VTTRC have not been discussed and investigated. A brazing sheet, which is used in automobile radiators, is an important application of the three-layer clad strip. The clad ratio of the brazing sheet is 1:8:1. The base strip of the brazing sheet is 3003 aluminium alloy and the overlay strips are 4045 aluminium alloy. In this paper, the casting conditions to control the clad ratio of the 3003 aluminium alloy and the 4045 aluminium alloy are discussed and the results of an experiment to produce the 1:8:1 clad ratio by the VTTRC are presented. An as-cast clad strip is cold-rolled down to the desired thickness. The effect of the cold rolling on the interface between the strips and clad ratio is also examined.

It is said that the cladding of Al-Mg alloy and other aluminium alloys by hot rolling is not easy due to formation of the oxide film. Therefore, the possibility of casting of the clad strip consisting of the Al-Mg alloy 
and other aluminium alloys by the VTTRC was investigated. It became clear that gaps at the interface of the clad strip occurred and a sound clad strip could not be cast by the VTTRC. It was concluded that the oxide film might interrupt the bonding of the strips. A scraper was proposed to prevent the influence of oxidation. The scraper was attached to one of the rolls of the vertical type twin roll caster. The vertical type twin roll caster equipped with the scraper (VTRCS) was proposed to cast the sound clad strip consisting of Al-Mg alloy and other aluminium alloys. The efficacy of the scraper in the casting of the clad strip consisting of the Al-Mg alloy and other aluminium alloys was investigated. Therefore, this paper also presents investigations of the casting conditions to control the clad ratio, the influence of the cold rolling and the scraper on the casting of the clad strip consisting of the Al-Mg alloy to estimate the efficacy of the twin roll caster in the making of clad strips.

\section{Experimental conditions}

\subsection{VTTRC}

The VTTRC is illustrated in Figure 1. Molten metal is poured through a launder from a crucible in the pool made by nozzle plates and side dam plates. The base strip is cast by the upper twin roll caster and the overlay strips are cast by the lower twin roll caster [2-4]. Casting the overlay strips and bonding them to the base strip are simultaneously carried out at the lower twin roll caster. The molten metal of the overlay strip is poured after the base strip is inserted between the rolls of the lower twin roll caster. Therefore, the melting point of the base strip must be higher than that of the overlay strip to prevent melting of the base strip at the lower twin roll caster [5]. The rolls are made of copper for better cooling. Parting material, which prevents adhesion of the strip to the roll, is not used in order to increase the heat transfer between the roll and the molten metal [6]. The solidification length is decided by the position of the nozzle plates.

\subsection{VTRCS}

The schematic illustration of the VTRCS is illustrated in Figure 2. The scraper is attached to prevent the two molten metals from mixing. The scraper turns around the pivot and is pushed by a constant load [7,8]. The scraper traces the thickness of the solidification layer, and the solidification layer is dragged between the scraper and the roll. An aluminium alloy that has a melting point higher than the other aluminium alloy is cast as the scribed strip A to prevent the melting of strip A by the heat from the other aluminium alloy B. Strip A makes contact with strip B without contacting the oxidizing atmosphere.

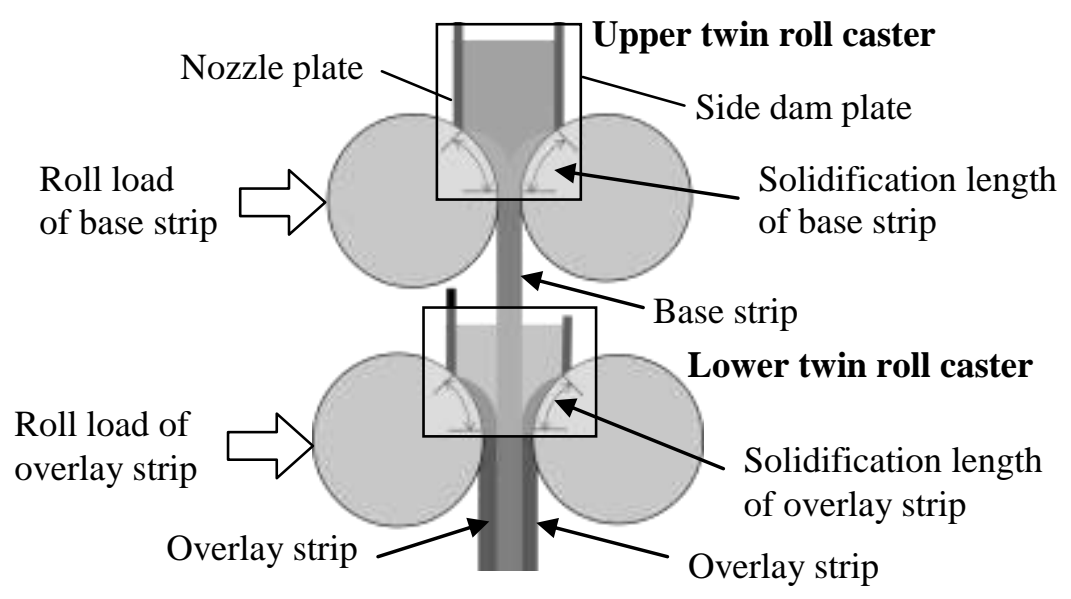

Fig. 1: Schematic illustration of the vertical type tandem twin roll caster (VTTRC). 


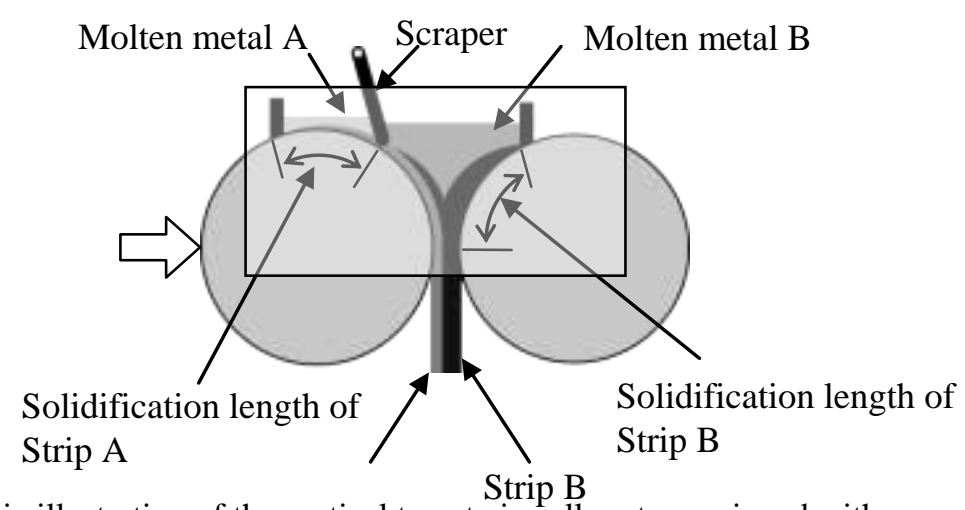

Fig. 2: Schematic illustration of the vertical type twin roll caster equipped with a scraper (VTRSC)

\subsection{Experimental conditions}

E In the vertical type twin roll caster of the present study, the copper rolls were used, although they were not strong enough to do hot rolling. Therefore, the thickness of the strip was controlled only by the roll speed and the solidification length. The strip becomes thinner as the roll speed becomes higher because the solidification time becomes shorter. The strip becomes thicker as the solidification length becomes longer because the solidification time becomes longer. In the clad strip casting using the VTTRC, the roll speeds of the upper and lower twin roll casters were the same. Therefore, thicknesses of the base strip and the overlay strip can be separately controlled by the solidification length. This means the clad ratio is controlled only by the solidification length.

The relationship between the solidification length, thickness of the solidification layer, and the clad ratio of the three-layer of clad strips cast by the VTTRC was investigated. In the brazing sheet for automobile radiators, the 3003 aluminium alloy is used for the base strip and the 4045 aluminium alloy is used for the overlay strips. Therefore, in this investigation, the 3003 aluminium alloy was used for the base strip and the 4045 aluminium alloy was used for the overlay strips.

The solidification length of the base strip was kept constant at $120 \mathrm{~mm}$, and that of the overlay strip was set at $25 \mathrm{~mm}, 40 \mathrm{~mm}$ and $60 \mathrm{~mm}$. The roll speed was $30 \mathrm{~m} / \mathrm{min}$. The roll load of the upper and lower twin roll casters was $55 \mathrm{~N} / \mathrm{mm}$. The pouring temperatures of the molten metals were set at $298 \mathrm{~K}$ above the liquidus line temperature. A bending test was carried out until the clad strip broke to investigate the influence of the clad ratio on the bonding condition. It is preferable that the clad ratio is not changed by the cold rolling, so the influence of cold rolling on the clad ratio was also investigated. An as-cast strip was cold-rolled down to $1 \mathrm{~mm}$. The condition of the interface between the strips was investigated by optical microscopy and line analysis. The ability of casting the clad strip consisting of the Al-Mg alloy and other aluminium alloys was investigated. A popular Al-Mg alloy is 5182 aluminium alloy. Therefore, the 5182 aluminium alloy was used in this study. Three-layer of clad strips were cast to investigate the bonding of the Al-Mg alloy strip by the VTTRC. In one case, the base strip was 3003 Al-Mn alloy and the overlay strips were 5182 Al-Mg alloy. In another case, the base strip was $5182 \mathrm{Al}-\mathrm{Mg}$ alloy and the overlay strips were $4045 \mathrm{Al}-\mathrm{Si}$ alloy.

Two-layer clad strips of 3003 aluminium alloy(scribed strip) and 5182 aluminium alloy, 4045 aluminium alloy and 5182 aluminium alloy(scribed strip) were also cast by the VTRCS to investigate the effect of the scraper on the bonding of the Al-Mg alloy strip. In these combinations of alloys, the melting point of the scribed strip was higher than that of the other strip. The roll speed was $30 \mathrm{~m} / \mathrm{min}$ and the roll loads were $55 \mathrm{~N} / \mathrm{mm}$ and $220 \mathrm{~N} / \mathrm{mm}$. The pushing load of the scraper was $1 \mathrm{~N} / \mathrm{mm}$. The chemical compositions of the alloys are shown in Table 1, and the solidus line temperatures and the liquidus line temperatures of the alloys are shown in Table 2. 
TABLE 1: Chemical compositions of the aluminium alloys (mass\%).

\begin{tabular}{lccccccc}
\hline \hline \multicolumn{1}{c}{ Alloy } & $\mathrm{Si}$ & $\mathrm{Fe}$ & $\mathrm{Cu}$ & $\mathrm{Mn}$ & $\mathrm{Mg}$ & $\mathrm{Zn}$ & $\mathrm{Al}$ \\
\hline 3003(Al-Mn) & 0.25 & 0.62 & 0.14 & 1.16 & 0.01 & 0.01 & bal. \\
4045(Al-Si) & 9.86 & 0.17 & 0.01 & 0.01 & 0.01 & 0.02 & bal. \\
5182(Al-Mg) & 0.05 & 0.14 & 0.11 & 0.42 & 4.75 & 0.01 & bal. \\
\hline \hline
\end{tabular}

TABLE 2: Solidus line temperatures and liquidus line temperatures of aluminium alloys.

\begin{tabular}{ccc}
\hline \hline Alloy & Solidus line temperature $(\mathrm{K})$ & Liquidus line temperature $(\mathrm{K})$ \\
\hline 3003(Al-Mn) & 916 & 927 \\
$4045(\mathrm{Al}-\mathrm{Si})$ & 850 & 863 \\
$5182(\mathrm{Al}-\mathrm{Mg})$ & 850 & 911 \\
\hline \hline
\end{tabular}

\section{Experimental conditions}

\subsection{VTTRC}

The three-layer clad strip with base strip 3003 aluminium alloy and overlay strips 4045 aluminium alloy could be cast continuously by the VTTRC. The cross section of the as-cast three-layer clad strip is shown in Figure 3 (a). The solidification length of the overlay strip was $25 \mathrm{~mm}$. The result of the line analysis around the interface between the strips is shown in Figure 3 (b). No gap occurred between the strips. The result of the line analysis shows that $\mathrm{Si}$, which is an element of the 4045 aluminium alloy strip, did not diffuse into the 3003 aluminium alloy strip. In addition, no mixture zone of the two alloys appeared, and the 3003 aluminium alloy was not melted by the heat of the 4045 aluminium alloy. These results show that the three-layer clad strip could be cast by the VTTRC without diffusion of the elements or mixing of the alloys at the interface. The cross section of the three-layer clad strip cold-rolled down to $1 \mathrm{~mm}$ is shown in Figure 3 (c). Peeling of the overlay strips from the base strip did not occur. The clad ratio of the cold-rolled strip was the same as that of the as-cast strip. The interface after cold rolling was clear and linear, and did not change. These results show that cold rolling can be used on three-layer clad strips cast by the VTTRC.

The relationship between the solidification length of the overlay strip, the thickness of the overlay strip, and the clad ratio is shown in Table 3. The clad ratio is the thickness of the base strip divided by the thickness of the overlay strip. The thickness of the base strip was kept constant at $4.7 \mathrm{~mm}$. The thickness of the overlay strip was controlled by the solidification length. Table 3 shows that the clad ratio could be controlled by the solidification length of the overlay strip. If the solidification length of the base strip is simultaneously controlled, the clad ratio can be controlled for a wider range. The conditions that influence the strip thickness are roll speed and solidification length in the twin roll caster. In the VTTRC, the roll speeds of the upper and lower twin roll casters must be the same. Therefore, the solidification length is the only condition that controls the clad ratio.

The results of the continuous bending test until breaking are shown in Figure 4. In Figure 4, the cross sections of the broken areas are shown. Three-layer clad strips having overlay strips of $0.6 \mathrm{~mm}$ (a) and $1.1 \mathrm{~mm}$ (b) were bent. Neither of the clad strips peeled at the interface. Therefore, the overlay strip was strongly bonded to the base strip. The thickness of the overlay did not influence the bonding condition.

The cross sections of the clad strips of the Al-Mg alloy cast by the VTTRC are shown in Figure 5. The 5182 aluminium alloy is a typical Al-Mg alloy. In the clad strip consisting of base strip 5182 aluminium alloy and overlay strips 4045 aluminium alloy shown in Figure 5 (a), porosities appeared in the 4045 aluminium alloy 
layer near the interface. The thickness of the layer with porosities was approximately $0.2 \mathrm{~mm}$. Si and Mg existed in this layer. It is supposed that the 5182 aluminium alloy melted from the heat of the 4045 aluminium alloy, and so a mixture of the 5182 aluminium alloy and the 4045 aluminium alloy was formed.

The pouring temperature of the 4045 aluminium alloy molten metal was lower than the liquidus line temperature of the 5182 aluminium alloy. The solidus line temperature of the 5182 aluminium alloy is the same as that of the 4045 aluminium alloy. The contact time of the 5182 aluminium alloy strip and the 4045 aluminium alloy molten metal was about 0.2 seconds. This contact time is thought to be very short. Nevertheless, melting of the 5182 aluminium alloy strip occurred. The latent heat of the 4045 aluminium alloy was released within the freezing zone of the 5182 aluminium alloy. The latent heat is 350 times larger than the specific heat. The surface of the 5182 aluminium alloy strip might have reached the semisolid condition by the latent heat of the 4045 aluminium alloy. Therefore, the mixture between the 5182 aluminium alloy and the 4045 aluminium alloy might have occurred. However, the cause of the porosities is not clear. The melting of 5182 aluminium alloy is prevented if the 5182 aluminium alloy has a solidus line temperature higher than the liquidus line temperature of the 4045 aluminium alloy, as in the clad strip consisting of the 3003 aluminium alloy and the 4045 aluminium alloy.

In the clad strip consisting of base strip 3003 aluminium alloy and overlay strips 5182 aluminium alloy by the VTTRC, the overlay 5182 aluminium alloy strips did not bond to the 3003 aluminium alloy strip at most of the interface, as shown in Figure 5 (b). The surface of the 3003 aluminium alloy strip is assumed to be covered with an oxide film, and so the surfaces of the 5182 aluminium alloy strips were easily oxidized by contacting the oxide film of the 3003 aluminium alloy strip. Therefore, the 5182 aluminium alloy strip did not bond to the 3003 aluminium alloy strip due to interaction of the oxide film.

The latent heat of the 5182 aluminium alloy is smaller than that of the 4045aluminum alloy. Therefore, the surface of the 3003 aluminium alloy strip might be not heated up to the temperature suitable for the bonding.

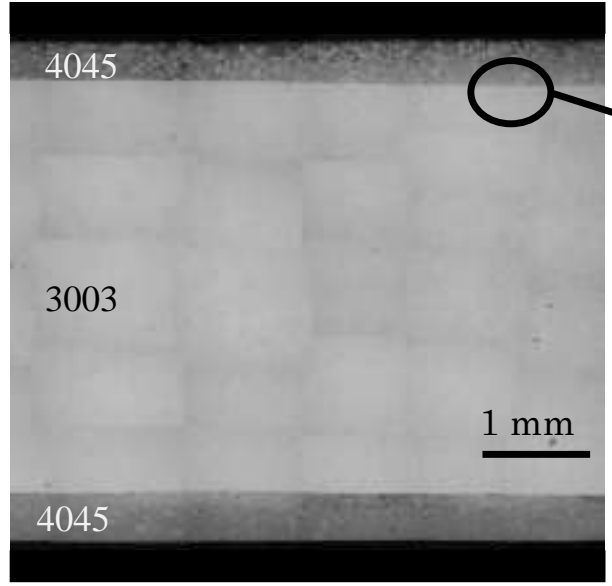

(a) cross section of three layers clad strip

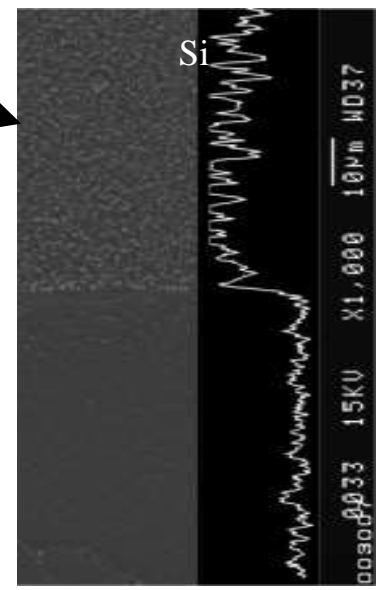

(b) line analysis of $\mathrm{Si}$

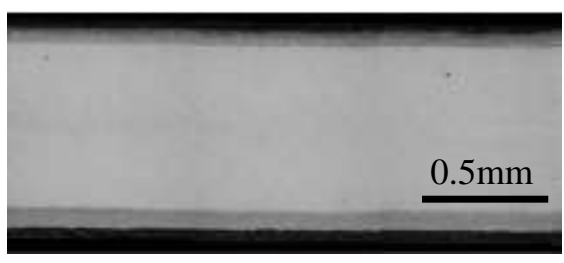

(c) cross section of the clad strip cold rolled down to $1 \mathrm{~mm}$

Fig. 3: Cross sections of as-cast and cold-rolled three-layer clad strips and the result of the line analysis of Si. The clad strips were cast by the VTTRC.

TABLE 3: Relationship among solidification length of the overlay strip, thickness of the overlay strip and the clad ratio. The thickness of the base strip was $4.7 \mathrm{~mm}$. The clad ratio is the thickness of the base strip divided by the thickness of the overlay strip. These dimensions apply to the VTTRC.

\begin{tabular}{ccc}
\hline \hline Solidification length of overlay strip $(\mathrm{mm})$ & Thickness of overlay strip (mm) & Clad ratio \\
\hline 25 & 0.56 & 8.4 \\
40 & 0.72 & 6.5 \\
60 & 1.10 & 4.3 \\
\hline \hline
\end{tabular}




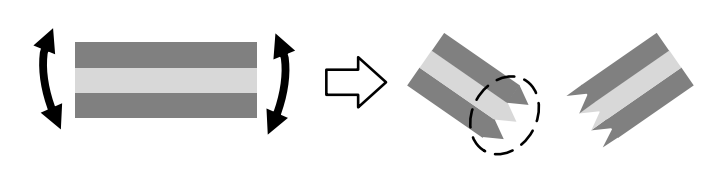

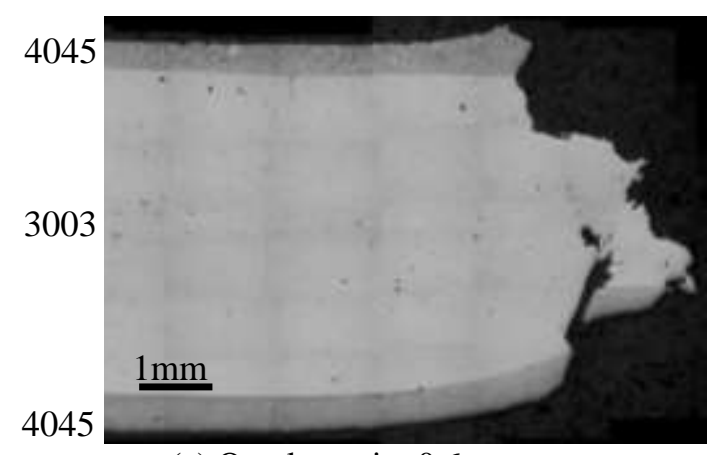

(a) Overlay strip: $0.6 \mathrm{~mm}$

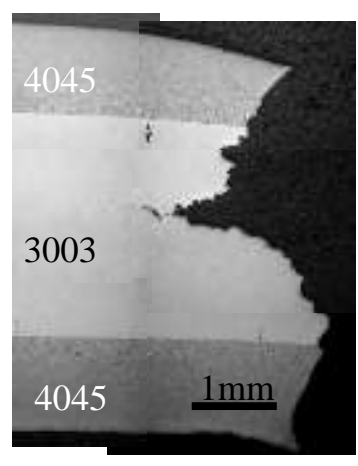

(b) Overlay strip: $01.1 \mathrm{~mm}$

Fig 4: Cross section of as-cast strip broken by continuous bending. The strips were cast by the VTTRC depicted in Figure 1.

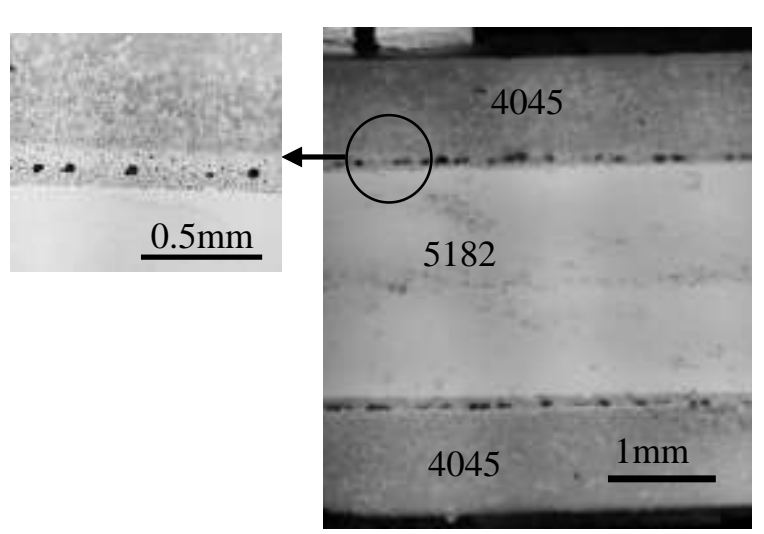

(a) Al-Mg alloy was base strip

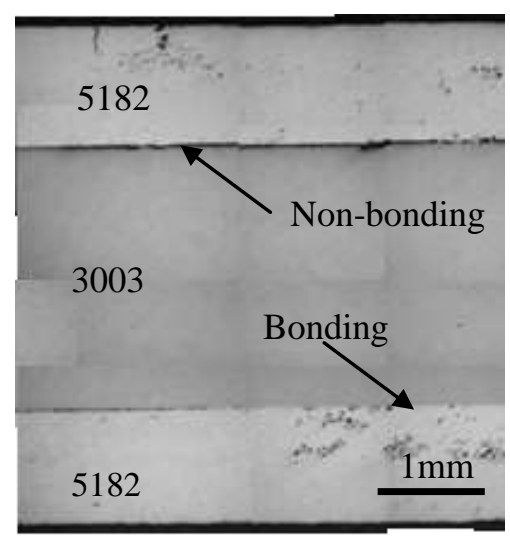

(b) Al-Mg alloy was overlay strip

Fig. 5: Cross sections of the as-cast clad strips of 5182(Al-Mg) and 4045(Al-Si), and of 5182(Al-Mg) and 3003(Al-Mn). The clad strips were cast by the VTTRC depicted in Figure 1.

\subsection{VTRCS}

Two-layer clad strip could be cast continuously by the VTRCS. The cross sections of the clad strips, including the Al-Mg alloy strips cast by the VTRCS, are shown in Figure 6. In the clad strip of the 4045 aluminium alloy and the 5182 aluminium alloy (scribed strip), melting of the 5182 aluminium alloy occurred and a mixture layer of the 5182 aluminium alloy and the 4045 aluminium alloy was made, as in the clad strip cast by the VTTRC (Figure 5). However, no porosity appeared at the mixed layer, as shown in Figure 6 (a). The reason is not clear. The 5182 aluminium alloy strip directly contacted the roll when bonded between the roll bite in the casting by the VTRCS. In the casting by the VTTRC, both surfaces of the 5182 aluminium alloy base strip contacted the 4045 aluminium alloy strips and were heated by the 4045 aluminium alloy strips. The cooling rate of the mixture layer may lead to the appearance of porosities.

The 5182 aluminium alloy strip could bond to the 3003 aluminium alloy strip (scribed strip) without a gap at the interface, as shown in Figure 6 (b) in the casting by the VTRCS. The scribed surface of the 3003 aluminium alloy strip was not even. However, no gap occurred. It is thought that the contact condition between the 3003 aluminium alloy strip and the 5182 aluminium alloy molten metal was satisfactory. Unevenness at the scribed surface did not influence the appearance of the gap and bonding of the strips, because surface temperature of the 3003 aluminium alloy strip was sufficiently high to realise good wetting condition. It is suggested that these improvements are due to the scraper, which kept both strips from contacting the oxidizing atmosphere. The 
VTRCS could improve the gap of the clad strip cast by the VTTRC. These results show the VTRCS is useful for the casting of the clad strip consisting of $\mathrm{Al}-\mathrm{Mg}$ and other aluminium alloys.

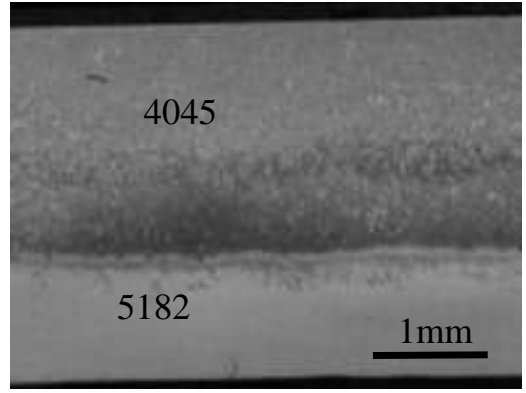

(a) 5182 strip was scribed

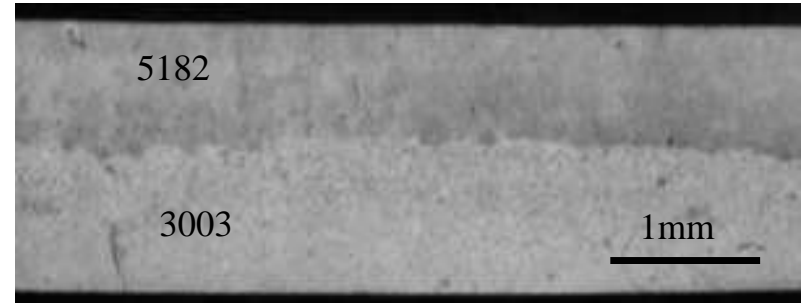

(b) 3003 strip was scribed

Fig. 6: Cross sections of the as-cast clad strips of $5182(\mathrm{Al}-\mathrm{Mg})$ and 4045(Al-Si), and of $5182(\mathrm{Al}-\mathrm{Mg})$ and 3003(Al-Mn). The clad strips were cast by the VTRCS depicted in Figure 2.

\section{Conclusions}

In this paper, the casting conditions to control the clad ratio of the 3003 aluminium alloy and the 4045 aluminium alloy are discussed and the results of an experiment to produce the 1:8:1 clad ratio by the VTTRC are presented. In the VTTRC, the clad ratio of a three-layer clad strip could be controlled by the solidification length. In the condition that the base strip was 3003 aluminium alloy and the overlay strips were 4045 aluminium alloy, the clad ratio of 1:8:1 was attained. This is a practical clad ratio. Bonding was not influenced by the clad ratio. The clad ratio was not changed by cold rolling. However, a sound clad strip consisting of Al-Mg and other aluminium alloys could not be cast. Porosities or gaps existed at the interfaces of the clad strips. It was supposed that the cause of the gaps was oxidation at the surfaces of the strip or insufficient heating at the surfaces of the base strip.

A scraper was attached to the vertical type twin roll caster to keep the strips from contacting the oxidizing atmosphere. This VTRCS was proposed to cast the sound clad strip consisting of Al-Mg alloy and other aluminium alloys. The efficacy of the scraper in the casting of the clad strip consisting of the Al-Mg alloy and other aluminium alloys was investigated. The VTRCS could cast a two-layer clad strip consisting of Al-Mg alloy and other aluminium alloys without porosities and gaps.

\section{Acknowledgements}

This research is supported from A-STEP AS2815035S by Japan Science and Technology Agency, JST.

\section{References}

[1] R. Nakamura, T. Yamabayashi, T. Haga, H. Watari and S. Kumai," Casting of aluminium alloy clad strip using a roll caster,",J.Solid Mech.Mater.Eng., Vol.5, pp. 1029- 1041, 2011. https://doi.org/10.1299/jmmp.5.1029

[2] T. Haga, M. Ikawa and S. Kumai, "A high speed twin roll caster for aluminium alloy thin strip," Transaction of the Materials Research Society of Japan, vol. 29, pp. 1823-1928, 2004. https://doi.org/10.1016/j.jmatprotec.2004.04.018

[3] T. Haga T and S. Suzuki, "Study on a high-speed twin roll caster for aluminium alloys," J.Mater. Process. Technol., Vol.143, pp. 895-900, 2003.

[4] T. Haga, K. Takahashi, M. Ikawa and H.Watari," Twin roll casting of aluminium alloy strips," J.Mater. Process. Technol., vol.153, pp. 42-46, 2004. https://doi.org/10.1016/j.jmatprotec.2004.04.018

[5] T. Haga and S. Suzuki," A twin roll caster to casting of clad strip," J. Mater. Process. Technol., vol.138, pp. 366-371, 2003 https://doi.org/10.1016/S0924-0136(03)00100-6. 
[6] S. Hamer, C. Romanowski and B. Taraglio, "Continuous casting and rolling of aluminium: Analysis of capacities, product ranges, and technology," Light Met. Age, vol.60, pp.6-17, 2002.

[7] T. Haga, K. Akitsu, T. Yamabayashi, S. Kumai and H. Watari," Strip casting by a single roll caster equipped with a scraper," Key Eng. Mater., Vol.443, pp. 122-127, 2010 https://doi.org/10.4028/www.scientific.net/KEM.443.122.

[8] T. Haga, M. Sawai, R. Nakamura, T. Yamabayashi, S. Kumai and H. Watari, "Roll casting of three layers clad strip," Key Eng. Mater., vol. 443, pp. 128-133, 2010.

https://doi.org/10.4028/www.scientific.net/KEM.443.128 